\title{
Parametric Optimization of the Poly (Nvinylcaprolactam) (PNVCL) Thermoresponsive Polymers Synthesis by the Response Surface Methodology and Radial Basis Function neural network
}

\author{
Marwah N. Mohammed ${ }^{1, ~ *, ~ K a m a l ~ B i n ~ Y u s o h ~}{ }^{1}$, Jun Haslinda Binti Haji Shariffuddin ${ }^{1}$ \\ ${ }^{1}$ Faculty of Chemical \& Natural Resources Engineering, Universiti Malaysia Pahang, 26300, Pahang, \\ Malaysia.
}

\begin{abstract}
A novel comparison study based on a radial basis function neural network (RBFNN) and Response Surface Methodology (RSM) is proposed to predict the conversion rate (yield) of the experimental data for PNVCL polymerization. A statistical and optimization model was performing to show the effect of each parameter and their interactions on the conversion rate. The influence of the time, polymerization temperature, initiator concentration and concentration of the monomer were studied. The results obtained in this study indicate that the RBFNN was an effective method for predicting the conversion rate. The time of the PNVCL polymerization as well as the concentration of the monomer show the maximum effect on the conversion rate. In addition, compared with the RSM method, the RBFNN showed better conversion rate comparing with the experimental data.
\end{abstract}

\section{Introduction}

The recognized thermosensitive polymer with LCST close to physical temperature is Poly (N-vinylcaprolactam) (PNVCL), which is around $32^{\circ} \mathrm{C}$ [1]-[3]. For biomedical applications, this type of physiological temperature considered promising especially in drug delivery systems and micro-encapsulation of enzymes or cells [4,5]. Since not long the poly (Nisopropylacrylamide) (PNIPAM) was the most of the environmental thermoresponsive polymer as a homo- and copolymers, but PNVCL has an exceptional advantage make him better than PNIPAM. these remarkable advantage has been proven by cytotoxicity evaluation which proved produce toxic low-molecular-weight amines during hydrolysis [6]. Likewise, there are other features of PNVCL as high complexing ability with different therapeutic agents; low toxicity and biocompatibility make it substantially propose utilized as a hydrophobic core-forming segment with different kinds of hydrophilic moieties at temperatures above its LCST. These features together are widely used in many medical and industrial applications, in special in the biomedical field [7]-[9].

* Corresponding author: marwahnoori85@gmail.com 
In manufacturing stage, the two significant issues are process modelling and optimization. For the optimization of process parameters, it is not only excess the product quality but advantage of also the advantage of technologist. Through the manufacturing process to produce polymers a multi-type problem can appear, to identify and summarize these problems the response surface methodology (RSM) utilize to be a simple and effective method of enhancing, analyzing and optimizing the parameter settings [10], [11].

The radical polymerization is the method which is used to synthesise PNVCL starting from the monomer. Although this polymer has a considerable attention the data information on its radical polymerization are rare and significant quantitative characteristics of the reaction are unavailable [12]-[14]. Therefore, the goal of the present study is to investigate the factors which are the effect on synthesis process.

\section{Experimental}

\subsection{Materials and polymerization procedure}

$\mathrm{N}$-vinylcaprolactam (98\%, provided by Aldrich) as a monomer, 2,20-azobisisobutyronitrileAIBN (supplied by BASF, Guaratingueta ', state of Sao Paulo, Brazil) as initiator, while 1,4dioxane $(99.8 \%$, Aldrich) as a solvent. The PNVCL polymer, was produced by free radical polymerization technique, in 1,4-dioxane at $70{ }^{\circ} \mathrm{C}$ for 3 hours, the experimental results were obtained by [15]. The reaction was performed under nitrogen atmosphere, in a double walled glass reactor and heated to reach $70{ }^{\circ} \mathrm{C}$ temperatures. At First, the calculated amount of Nvinylcaprolactam was poured in to the reactor, in addition to a suitable volume of internal standard (Trioxane). After the addition of $75 \%$ of the 1,4-dioxane, the solution was flushed with argon for almost 20 minutes. A mixed solution of AIBN and the solvent (remaining $25 \%$ ) was processed and flushed with argon for $\sim 20$ minutes. When the temperature reached $70{ }^{\circ} \mathrm{C}$, the polymerization was commenced by adding the prepared AIBN solution. The polymerization was carried out for 3 hours at $70^{\circ} \mathrm{C}$.

\subsection{Experimental design}

Response Surface Methodology (RSM) is a usual experimental design technique for optimization of the chemical engineering processes [16]-[18]. This method is also employed to find out conditions leading to a product with enhanced characteristics or quality [19]-[21]. The present study was aimed to develop the input-output relationships for prediction of the conversion \% for PNVCL polymerization. In order to achieve at the most influential variables and its effects a phase parameters were proposed. Response surface methodology (RSM) based on central composite design (CCD) was utilized to develop a model for prediction of the conversion \% for PNVCL polymerization from the experimental data. RSM are used to estimate the transfer functions at the optimal region. Hence, CCD approach was selected for the present study. The use of statistical design of experiment (DOE) techniques provides with valuable tools for forecasting the behavior of a system or process [22]-[25].

\subsection{RBFNN Optimization Technique}

Lowe [26] were a first suggestion the Radial Basis Function neural network (RBFNN), and their interpolation and generalization properties are thoroughly investigated in [26]. RBFNN is an artificial neural network depends on radial basis functions as activation functions; the output of the network is a linear combination of radial basis functions of the inputs and neuron parameters a linear combination of radial basis functions. RBFNN applied on different fields 
like a mathematical modelling, pattern classification, approximation of a nonlinear function, control, and time-series prediction. RBFNN able to approximate any reasonable continuous function mapping and reaches a good degree of accuracy [27]-[29]. RBFNN formation from three various layers with feedforward architecture: the input layer, hidden layer (RBFNN), and the output layer. Figure 1 illustrates RBFNN structure.

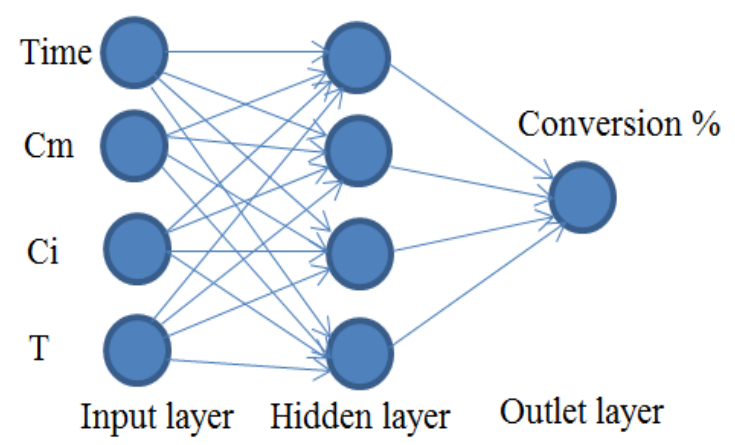

Fig. 1. Radial basis function neural network (RBFNN) structure.

The RBFNN, as a typical feed-forward network, has been found to be very beneficial to many engineering problems [30]. It consists of three layers: the input layer, hidden layer, and output layer. In this study, the activation function ([f(x)]), used as a Gaussian type, and was as follows [31]:

$$
\emptyset(x)=\exp \left[\frac{\left\|x-c_{i}\right\|}{2 \sigma_{i}^{2}}\right]
$$

where, $\left(c \_i\right)$ and $\left(\sigma \_i\right)$ denote the center and spread width of the (i-th) node, respectively, thus $\left(\left\|x-c \_i\right\|\right)$ is the Euclidean distance between input vector $(x)$ and center (c_i) $[32,33]$.

In the current study used MATLAB computer software for optimization. Have been identified (time, $\mathrm{Cm}, \mathrm{Ci}$, Temperature) as the inputs of hidden layer (X), and the output conversion $\%$ as the output layer (Y) which requires optimizing.

\section{Results and Discussion}

This research aims to enhance the input and output relationships for prediction of the Conversion rate (yield), the inlet and outlet experimental data for PNVCL polymerization shown in table 1 . The analysis of variance (ANOVA) results are presented in Table 2. It can be seen that the model F-value of 26.63 implies the model is significant. There is only a $0.0001 \%$ chance that a "Model F-Value" this large could occur due to noise. Values of "Prob $>\mathrm{F}^{\prime \prime}$ less than 0.0500 indicate model terms are significant. In this case Time, Temp. and Time2 are significant model terms. Values greater than 0.1000 indicate the model terms are insignificant. Values greater than 0.1000 indicate the model terms are not significant. 
Table 1. Experimental data for PNVCL polymerization [15].

\begin{tabular}{|c|c|c|c|c|}
\hline Time (min) & $\mathrm{Cm}(\mathrm{mol} / \mathrm{L})$ & $\mathrm{Ci}(\mathrm{mol} / \mathrm{L})$ & $\mathrm{T}\left({ }^{\circ} \mathrm{C}\right)$ & Conversion \% \\
\hline 45 & 0.16 & 0.031 & 70 & 78 \\
\hline 150 & 0.16 & 0.023 & 60 & 73 \\
\hline 180 & 0.16 & 0.023 & 80 & 100 \\
\hline 150 & 0.16 & 0.0235 & 80 & 96 \\
\hline 20 & 0.16 & 0.016 & 60 & 21 \\
\hline 180 & 0.16 & 0.023 & 60 & 80 \\
\hline 15 & 0.16 & 0.031 & 70 & 31 \\
\hline 45 & 0.32 & 0.023 & 70 & 71 \\
\hline 120 & 0.32 & 0.023 & 70 & 90 \\
\hline 90 & 0.16 & 0.023 & 80 & 86 \\
\hline 45 & 0.16 & 0.023 & 80 & 69 \\
\hline 60 & 0.32 & 0.023 & 70 & 78 \\
\hline 30 & 0.16 & 0.023 & 70 & 48 \\
\hline 150 & 0.16 & 0.0235 & 70 & 94 \\
\hline 90 & 0.16 & 0.023 & 60 & 50 \\
\hline 180 & 0.32 & 0.023 & 70 & 100 \\
\hline 60 & 0.16 & 0.023 & 80 & 75 \\
\hline 30 & 0.16 & 0.023 & 60 & 27 \\
\hline 60 & 0.16 & 0.016 & 70 & 63 \\
\hline 20 & 0.32 & 0.023 & 70 & 42 \\
\hline 90 & 0.06 & 0.023 & 60 & 61 \\
\hline 90 & 0.16 & 0.023 & 70 & 73 \\
\hline 180 & 0.16 & 0.016 & 70 & 91 \\
\hline 90 & 0.32 & 0.031 & 70 & 87 \\
\hline 120 & 0.16 & 0.031 & 70 & 96 \\
\hline 15 & 0.16 & 0.016 & 70 & 19 \\
\hline 90 & 0.32 & 0.023 & 80 & 88 \\
\hline 30 & 0.06 & 0.023 & 70 & 47 \\
\hline 180 & 0.16 & 0.031 & 70 & 100 \\
\hline 120 & 0.16 & 0.023 & 80 & 93 \\
\hline
\end{tabular}


Table 2. Analysis of variance (ANOVA) results of the yield.

\begin{tabular}{|c|c|c|c|c|c|}
\hline Source & Sum of Squares & df & Mean Square & F value & p-value Prob > F \\
\hline Model & 25146.4 & 14 & 1796.17 & 26.63 & $\begin{array}{l}<0.0001 \\
\text { significant }\end{array}$ \\
\hline A-Time & 12341.9 & 1 & 12341.9 & 182.95 & $<0.0001$ \\
\hline B-Cm & 102.77 & 1 & 102.77 & 1.52 & 0.2374 \\
\hline C-Ci & 132.73 & 1 & 132.73 & 1.97 & 0.1825 \\
\hline D-Temp & 643.16 & 1 & 643.16 & 9.53 & 0.008 \\
\hline AB & 81.1 & 1 & 81.1 & 1.2 & 0.2914 \\
\hline AC & 2.73 & 1 & 2.73 & 0.04 & 0.8436 \\
\hline AD & 25.86 & 1 & 25.86 & 0.38 & 0.5458 \\
\hline BC & 112.3 & 1 & 112.3 & 1.66 & 0.2179 \\
\hline BD & 12.26 & 1 & 12.26 & 0.18 & 0.6763 \\
\hline CD & 102.01 & 1 & 102.01 & 1.51 & 0.2391 \\
\hline A2 & 2550.31 & 1 & 2550.31 & 37.81 & $<0.0001$ \\
\hline B2 & 20.02 & 1 & 20.02 & 0.3 & 0.5945 \\
\hline C2 & 41.82 & 1 & 41.82 & 0.62 & 0.4442 \\
\hline D2 & 96.67 & 1 & 96.67 & 1.43 & 0.2511 \\
\hline Residual & 944.43 & 14 & 67.46 & & \\
\hline Cor Total & 26090.8 & 28 & & & \\
\hline & & & & & \\
\hline
\end{tabular}

The mathematical model for the conversion rate $(\%)$ is developed based on the response surface method. The mathematical equation of the conversion rate (\%) can be expressed as in Eq. (2).

$$
\begin{gathered}
\text { Conversion } \%=-123.28278+1.36579 * \mathrm{~T} 1+362.07716 * \mathrm{X} 2 \\
-13759.21200 * \mathrm{X} 3+5.45449 * \mathrm{X} 4 \\
-0.27568 * \mathrm{X} 1 * \mathrm{X} 2-3.44569 * \mathrm{X} 1 * \mathrm{X} 3 \\
-4.79058^{*} 10^{\wedge}(-3) * \mathrm{X} 1 * \mathrm{X} 4-7772.07490 * \mathrm{X} 2 * \mathrm{X} 3 \\
-4.66738^{*} \mathrm{X} 2 * \mathrm{X} 4+206.38658 * \mathrm{X} 3 * \mathrm{X} 4 \\
-2.75566 * 10^{\wedge}(-3) * \mathrm{X} 1{ }^{\wedge} 2+470.91392^{*} \mathrm{X} 2{ }^{\wedge} 2 \\
+38677.86803^{*} \mathrm{X} 3^{\wedge} 2-0.054149^{*} \mathrm{X} 4^{\wedge} 2 ;
\end{gathered}
$$

The R-Squared analysis result of the conversion rate $\mathrm{t}$ is tabulated in Table 3 . The Predict R-Squared of 0.9638 is in reasonable agreement with the Adjusted R-Squared of 0.9276. Adequate Precision measures the signal to noise ratio. A ratio greater than 4 is desirable. The ratio of 15.389 indicates an adequate signal. This model can be used to navigate the design space of the meausre the conversion rate. The higher value of $\mathrm{R}^{2}$ indicates the better fit of the model with the real data.

Table 3. R2 analysis results of the conversion.

\begin{tabular}{|l|c|l|l|}
\hline Std. Dev. & 8.21 & R-Squared & 0.9638 \\
\hline Mean & 63.62 & Adj R-Squared & 0.9276 \\
\hline C.V. $\%$ & 12.91 & Pred R-Squared & N/A \\
\hline PRESS & N/A & Adeq Precision & 15.389 \\
\hline
\end{tabular}


The result from RBFNN and DOE was shown in the Table 4. This table highlights the conversion rate for three cases as an experimental, RBFNN predicated and RSM predicated. It was very clear the results from the RBFNN predicated closed to the experimental compared with the RSM predicated data. These results also presented in the Figure 2 to show that the RBFNN predicated results were correspond with experimental data exactly.

Table 4. Result from RBFNN and DOE.

\begin{tabular}{|l|l|l|l|l|l|l|l|l|}
\hline $\begin{array}{l}\text { Time } \\
(\mathrm{min})\end{array}$ & $\begin{array}{l}\mathrm{Cm} \\
(\mathrm{mol} / \mathrm{L})\end{array}$ & $\begin{array}{l}\mathrm{Ci} \\
(\mathrm{mol} / \mathrm{L})\end{array}$ & $\begin{array}{l}\mathrm{T} \\
\left({ }^{\circ} \mathrm{C}\right)\end{array}$ & $\begin{array}{l}\text { Conv. } \\
\%\end{array}$ & RBFNN & DOE & $\mathrm{E} 1$ & $\mathrm{E} 2$ \\
\hline 150 & 0.16 & 0.023 & 60 & 73 & 73 & 75.69 & 0 & -2.69 \\
\hline 20 & 0.16 & 0.016 & 60 & 21 & 21 & 20.7 & 0 & 0.3 \\
\hline 15 & 0.16 & 0.031 & 70 & 31 & 31 & 43.4 & 0 & -12.4 \\
\hline 120 & 0.32 & 0.023 & 70 & 90 & 90 & 95.69 & 0 & -5.69 \\
\hline 45 & 0.16 & 0.023 & 80 & 69 & 69 & 65 & 0 & 4 \\
\hline 90 & 0.16 & 0.023 & 60 & 50 & 50 & 58.1 & 0 & -8.1 \\
\hline 60 & 0.16 & 0.016 & 70 & 63 & 63 & 57.9 & 0 & 5.12 \\
\hline 180 & 0.16 & 0.016 & 70 & 91 & 91 & 90.25 & 0 & 0.74 \\
\hline 120 & 0.16 & 0.031 & 70 & 96 & 96 & 96.72 & 0 & -0.72 \\
\hline 180 & 0.16 & 0.031 & 70 & 100 & 100 & 99.89 & 0 & 0.11 \\
\hline
\end{tabular}

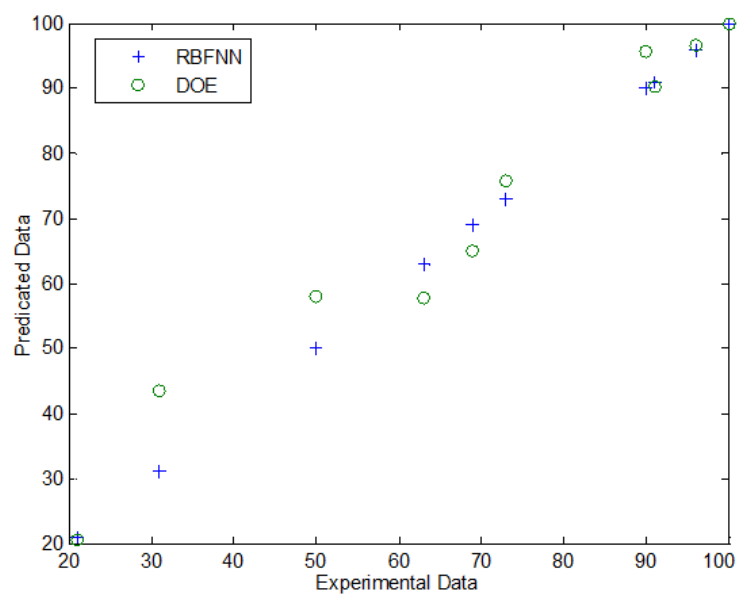

Fig. 2. The best fit line plot of the yield.

\section{Conclusion}

The application of RSM utilizing a central composite design (CCD) was investigated to elevate the affecting of the polymer conversion by polymerization factor. On the other hand, this study focuses on the predicated data from RBFNN optimization technique. All parameters showed a significant influence on the conversion rate, through ANOVA analysis. The predicted conversion rate show $0 \%$ error compared with the experimental results. Therefore, the RBFNN technique represents the more suitable optimization methods to manage the calculations of the conversion rate of the experimental data for the PNVCL polymerization. 


\section{References}

1. Prabaharan, M., et al., Macromol. Biosci., 8(9): p. 843-851 (2008).

2. Konefał, R., et al., Colloid. Polym. Sci., p. 1-10 (2016).

3. Yang, Y., et al., J. Polym. Res., 21(9): p. 1-9 (2014).

4. Loos, W., et al., Macromol. Chem. Phys., 204(1): p. 98-103 (2003).

5. Verbrugghe, S., K. Bernaerts, and F.E. Du Prez, Macromol. Chem. Phys., 204(9): p. 1217-1225 (2003).

6. Sun, S. and P. Wu, J. Phys. Chem. B, 115(40): p. 11609-11618 (2011).

7. Hurtgen, M., et al., J. Polym. Sci. Pol. Chem., 50(2): p. 400-408 (2012).

8. Lequieu, W., N. Shtanko, and F. Du Prez, J. Membrane Sci., 256(1): p. 64-71 (2005).

9. Dimitrov, I., et al., Prog. Polym. Sci., 32(11): p. 1275-1343 (2007).

10. Toloza Porras, C., et al., Macromol. React. Eng., 7(7): p. 311-326 (2013).

11. Wang, L. and L.J. Broadbelt, Macromolecules, 42(20): p. 7961-7968 (2009).

12. Solomon, O.F., M. Corciovei, and C. Boghin „, J. Appl. Polym. Sci., 12(8): p. 1843-1851 (1968).

13. Solomon, O., D. Vasilescu, and V. Tărărescu, J. Appl. Polym. Sci., 13(1): p. 1-7 (1969).

14. Kalugin, D., Y.A. Talyzenkov, and M. Lachinov, Polym. Sci. Ser. B+, 50(11-12): p. 299304 (2008).

15. Medeiros, S.F., et al., J. Appl. Polym. Sci., 118(1): p. 229-240 (2010).

16. Jenkins, A.L., M.W. Ellzy, and L.C. Buettner, J. Mol. Recognit., 25(6): p. 330-335 (2012).

17. Asghari, A., M. Kamalabadi, and H. Farzinia, Chem. Biochem. Eng. Q., 26(2): p. 145154 (2012).

18. Madaeni, S. and S. Koocheki, Chem. Eng. J., 119(1): p. 37-44 (2006).

19. Kaladhar, M., et al., J. Eng. Sci. Technol. Rev., 4(1): p. 55-61 (2011).

20. Mohamed, A.A., et al., J. Nucl. R. Technol., 9(1): p. 23-32 (2012).

21. Mehdinia, A., et al., J. Chromatogr. A, 1283: p. 82-88 (2013).

22. Cui, F., et al., Biotechnol. Bioproc. E., 15(2): p. 299-307 (2010).

23. San, F.G.B., I. Isik-Gulsac, and O. Okur, Energy, 55: p. 1067-1075 (2013).

24. Khamforoush, M., et al., Korean J. Chem. Eng., 31(9): p. 1695-1706 (2014).

25. Mirmohseni, A., M. Shojaei, and R. Pourata, RSC Adv., 4(39): p. 20177-20184 (2014).

26. Lowe, D., Compl. Syst., 2: p. 321-355 (1988).

27. Wang, S., et al., Entropy, 17(8): p. 5711-5728 (2015).

28. Jiao, G., T. Guo, and Y. Ding, Water, 8(9): p. 367 (2016).

29. Wang, X., et al., RSC Adv., 5(81): p. 66168-66177 (2015).

30. Rostamizadeh, K., H. Abdollahi, and C. Parsajoo, Int. Nano Lett., 3(1): p. 1-9 (2013).

31. Erol, R., et al., J. Med. Syst., 32(3): p. 215-220 (2008).

32. Evans, P., et al., Sensor. Actuat. B-Chem., 69(3): p. 348-358 (2000).

33. Ghosh-Dastidar, S., H. Adeli, and N. Dadmehr, IEEE T Bio-Med. Eng., 55(2): p. $512-$ 518 (2008). 